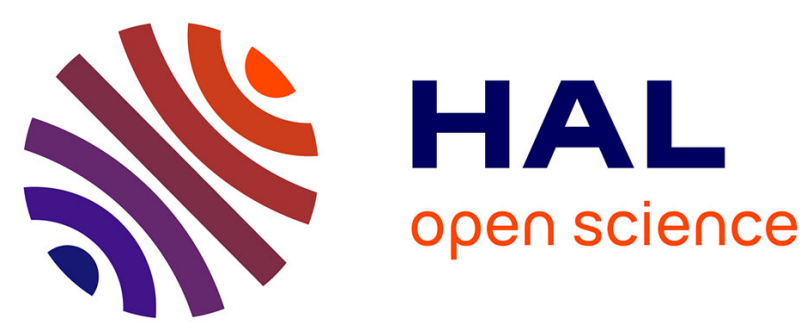

\title{
Seismic and electrical anisotropy in the Mornos delta, Gulf of Corinth, Greece, and its relationship with GPS strain measurements
}

Pascal Bernard, G. G Chouliaras, A. Tzanis, Pierre Briole, M.-P. Bouin, J Tellez, G. Stravakakis, K. Makropoulos

\section{To cite this version:}

Pascal Bernard, G. G Chouliaras, A. Tzanis, Pierre Briole, M.-P. Bouin, et al.. Seismic and electrical anisotropy in the Mornos delta, Gulf of Corinth, Greece, and its relationship with GPS strain measurements. Geophysical Research Letters, 1997, 24 (17), pp.2227-2230. 10.1029/97GL02102 . hal-01415909

\author{
HAL Id: hal-01415909 \\ https://hal.science/hal-01415909
}

Submitted on 9 Jun 2017

HAL is a multi-disciplinary open access archive for the deposit and dissemination of scientific research documents, whether they are published or not. The documents may come from teaching and research institutions in France or abroad, or from public or private research centers.
L'archive ouverte pluridisciplinaire HAL, est destinée au dépôt et à la diffusion de documents scientifiques de niveau recherche, publiés ou non, émanant des établissements d'enseignement et de recherche français ou étrangers, des laboratoires publics ou privés. 


\title{
Seismic and electrical anisotropy in the Mornos delta, Gulf of Corinth, Greece, and its relationship with GPS strain measurements
}

\author{
P. Bernard,${ }^{1}$ G. Chouliaras, ${ }^{2}$ A. Tzanis, ${ }^{3}$ P. Briole,${ }^{1}$ M.-P. Bouin,${ }^{1}$ J. Tellez,${ }^{4}$ \\ G. Stavrakakis, ${ }^{2}$ and K. Makropoulos ${ }^{3}$
}

\begin{abstract}
Shear-wave splitting studies on seismograms from local earthquakes at the site of the Mornos delta (Gulf of Corinth, Greece) has revealed a clear seismic anisotropy, with a fast $\mathbf{S}$ polarization striking $N 55 \pm 25^{\circ}$. Magneto-telluric soundings in the frequency range 0.01 to $100 \mathrm{~Hz}$ on the delta showed a clear electric anisotropy, with a $N 55^{\circ} \pm 10^{\circ}$ direction for the highest frequency. This anisotropy spans through the whole layer of sediments, about $1 \mathrm{~km}$ thick. Comparison of the 1966-1972 triangulations and the 1991-1995 GPS positions of geodetic points in and around the delta showed rapid extension strain $\left(2 \times 10^{-6} /\right.$ year $)$ in the direction $N 340^{\circ} \pm 30^{\circ}$, perpendicular to the fast $\mathrm{S}$ and the highest conductivity directions, suggestive of a causal relationship between these observations. We thus propose that this strain controls the two reported anisotropies, by the formation and maintaining of fluid filled, steeply dipping antithetic faults and fractures, and fluid filled vertical cracks, all striking $N 55^{\circ} \pm 20^{\circ}$. The source of strain is likely to be active normal faulting near and under the delta, as independently evidenced by the recent discovery of nearby offshore faults, striking about $N 60^{\circ}$, significantly different from the dominant $\mathrm{E}-\mathrm{W}$ strike of the major faults of the Gulf.
\end{abstract}

\section{Introduction}

A number of recent studies have revealed seismic anisotropy in the upper crust, mostly based on the analysis of shear wave splitting from local earthquakes. Crampin (1978) suggested that it is related to fluid filled rracks aligned in the stress field, proposing the EDA model (Extensive Dilatancy Anisotropy). Several field studies have supported this model, showing that the fast $\mathrm{S}$ direction was close to the regional compressive stress deduced from seismotectonic studies (e.g., Booth et al., 1985; Bouin et al., 1995). However, this model fails in some cases, and alternative models with layering of rocks in sediments, foliation in the rock fabric, or crystal preferential orientation have been proposed (e.g., Aster and Shearer, 1992).

\footnotetext{
${ }^{1}$ Institut de Physique du Globe de Paris

${ }^{2}$ National Observatory of Athens

${ }^{3}$ University of Athens

${ }^{4}$ Universidad Complutense de Madrid
}

Copyright 1997 by the American Geophysical Union.

Paper number 97GL02102.

0094-8534/97/97GL-02102\$05.00
In contrast to these numerous studies, very few attempts to detect electrical anisotropy in the upper crust and correlate it with seismic anisotropy have been reported (Evans et al.., 1987; Tzanis et al., 1995), a major reason being the strong sensitivity of the electrical methods to large-scale lateral heterogeneities, masking the anisotropy effect. We however believe that under favourable conditions, the electrical approach may bring very valuable, complementary information to the seismic anisotropy, due to its depth resolution with period and to the large range of resistivies of rocks, in particular due to fluid inclusions in cracks.

In the present study, we report and compare seismic and electrical anisotropy of the shallow crust at a site where we do not expect strong lateral heterogeneties, and where we could constrain the strain by GPS measurements. We selected the delta of the Mornos river, on the northern coast of the Gulf of Corinth (Greece), where a temporary experiment in 1991 has revealed a clear shear-wave splitting, interpreted as a crackinduced anisotropy in the sediments in relationship with the extensional strain of the area (Bouin et al., 1996).

\section{Tectonic setting of the Mornos delta}

The delta of the Mornos river is located on the northern coast of the Gulf of Corinth, near its western end (Figure 1). The gulf is an asymmetric rift, and one of the most active continental, tectonic structure in the Euro-Mediterranean area (Armijo et al., 1996) . It consists of major active normal faults outcropping along its southern coast, dipping to the north, and secondary antithetic faults outcropping on its northern side. GPS observations indicate $1.5 \pm 0.3 \mathrm{~cm} /$ year of extension of the western part of the rift in the direction $N 10^{\circ}$, confined to a narrow zone centered on the gulf axis (Briole et al., 1996). This direction is in good agreement with the NNE-SSW mean direction of the $T$ axis from the focal mechanisms (Rigo et al., 1996), and with the orientation and mechanism of the major normal faults. This high strain rate is accompanied by a strong microseismic activity, and numerous moderate to large earthquakes.

In the central part of the gulf, the sea reaches 800 $m$ in depth, due to the regular subsidence of the normal fault hanging wall since the Pleistocene. However, more to the west, the depth as well as the width of the gulf are smaller, owing to the more recent activation of the faults. At the western end of the gulf, the delta sediments brought by the Mornos river locally decrease the water depths to less than $100 \mathrm{~m}$. The Mornos delta, possibly about $1 \mathrm{~km}$ thick, is a nearly flat surface, about $5 \mathrm{~km}$ in diameter, gently dipping towards the south. It reaches the height of $10 \mathrm{~m}$ above sea level at about 2 


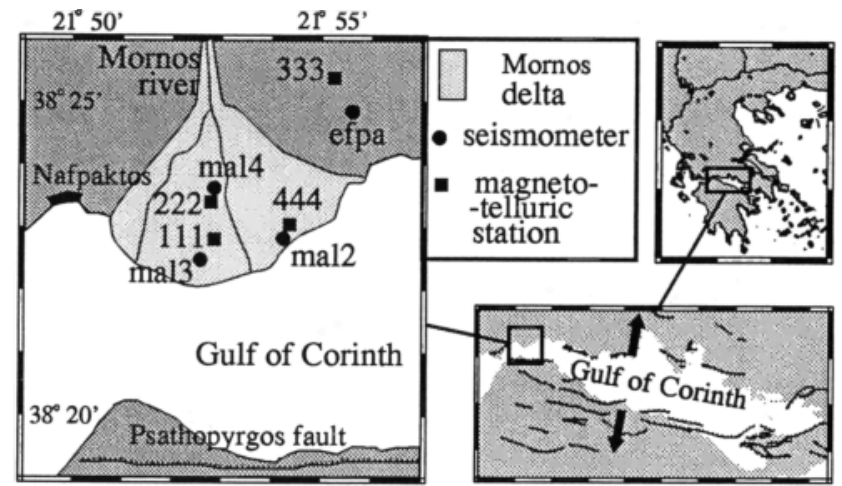

Figure 1. Location of the magnetotelluric and seismic stations on and near the Mornos delta. The black arrows are the directions of extension of the Corinth rift (see text). Faults are from Armijo et al. (1996).

$\mathrm{km}$ from the shore line. To the southwest of the delta, the water depths increases slowly; in contrast, to the southeast, the sea floor is $150 \mathrm{~m}$ deep at $1 \mathrm{~km}$ offshore.

\section{Seismic anisotropy}

A microseismic survey has been conducted in July and August 1991 around the western part of the Gulf of Corinth (Rigo et al., 1996). Shear-wave splitting from local earthquakes was observed at several sites, with a fast $\mathrm{S}$ axis mostly in the WNW-ESE (Bouin et al., 1996). Station mal2, located on the sediments of the delta (Figure 1 and Table 1), showed the strongest shear-wave splitting, with a typical $0.1 \mathrm{~s}$ delay, and a fast $\mathrm{S}$ polarization at $N 66^{\circ} \pm 25^{\circ}$. A typical example is given in Bouin et al. (1996). The delays do not show any clear dependence on distance.

Two other sites on the sediments of the delta (mals and mal/4 and one on the bedrock at its norteastern edge (efpa) were installed during a short seismic experiment in 1994 conducted by NOA and IPGP (Figure 1). About 30 local earthquakes were recorded at less than $10 \mathrm{~km}$ of hypocentral distance (estimated with S-P delays), but none could be located. The few records at mal/ presenting first shear waves impulsive enough for allowing a proper analysis of their polarization provided a similar result as for male: a fast $S$ wave polarized in the $N 40^{\circ}$ direction, and $0.05 \mathrm{~s}$ to $0.1 \mathrm{~s}$ delay (see Figure 2). No records could be used for mals in terms of shearwave splitting. On the limestone bedrock (efpa), the $\mathrm{S}$ waveforms were systematically perturbed by the arrival of an energetic phase with a significant vertical compo-

Table 1. Site locations and anisotropy directions

\begin{tabular}{lccc}
\hline site & long. $\left(^{\circ}\right)$ & lat. $\left({ }^{\circ}\right)$ & strike $\left(^{\circ}\right)$ \\
\hline mal2 & 21.904 & 38.380 & 66 \\
mal3 & 21.877 & 38.376 & no data \\
mal4 & 21.881 & 38.389 & 40 \\
efpa & 21.927 & 38.414 & 105 \\
111 & 21.881 & 38.38 & 55 \\
222 & 21.88 & 38.39 & 25 \\
333 & 21.921 & 38.423 & 55 \\
444 & 21.906 & 38.384 & 55 \\
\hline
\end{tabular}

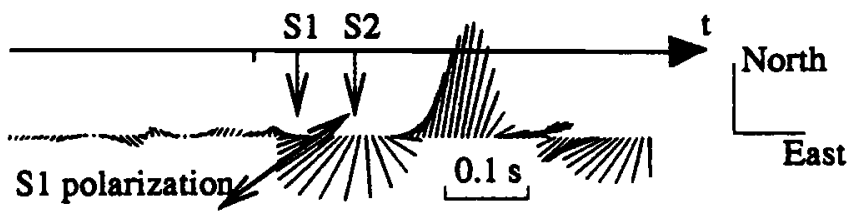

Figure 2. Example of shear-wave splitting at mal4. Polarigram of the S-wave in the $(\mathrm{N}, \mathrm{E})$ plane. Arrow S1 (resp. S2) shows the fast $\mathbf{S}$ (resp. slow $\mathrm{S}$ ) arrival time.

nent, just before or just after the first $S$ onset, which is likely to result from a strong conversion or scatter of the incident $S$ wave on a shallow, local heterogeneity. For the seismograms with a late arrival of this phase, the supposedly unperturbed first $S$ polarization showed a $N 105^{\circ}$ polarization direction, in agreement with other sites more to the east (Bouin et al., 1996).

The fast $\mathbf{S}$ direction on the delta sites is thus significantly different from the WNW-ESE regional compressive axis. Crack-induced anisotropy controlled by the mean regional stress thus does not provide an acceptable model, which implies either a local rotation of the stress direction within or below the sediments of the delta, or a structural anisotropy different from EDA.

\section{Electric anisotropy}

The magnetotelluric (MT) data was acquired in the fall of 1994 at four locations near the seismometer sites (Figure 1 and Table 1) by the University of Athens and NOA. Fairly standard data acquisition and tensor estimation procedures were applied to the five cartesian components of the natural electromagnetic (EM) field over the nominal frequency bandwidth 100-0.01 Hz. The analysis of Groom and Bailey (1989) indicates the absence of galvanic distortion, thus also ruling out the possibility of strong influence from current channelling in the gulf of Corinth. A typical example (site 111) is shown in Figure 3. The very low value of skew $(<0.1)$ and ellipticity $(<0.5)$ indicate a geoelectric structure with a geometry not higher than 2-D and weak to moderate effects on the propagation of the EM field. The structure is overall conductive and the apparent resistivity anisotropy (the ratio of maximum to minimum apparent resistivities) changes from about 2 at $0.01 \mathrm{~s}$ (depth of $80 \mathrm{~m}$ approx.) to about 5 at $0.3 \mathrm{~s}$ (depth of $600 \mathrm{~m}$ approx.). At depths greater than 600 $\mathrm{m}$, there is a change to a more resistive structure, which may correspond either to a transition to more compact, less hydrous delta sediments, or to the upper part of

Table 2. $1969-1993$ displacements

\begin{tabular}{cccrcc}
\hline site & $\begin{array}{c}\text { long. } E \\
\left({ }^{\circ}\right)\end{array}$ & $\begin{array}{c}\text { lat. N } \\
\left({ }^{\circ}\right)\end{array}$ & $\begin{array}{c}\text { alt. } \\
(\mathrm{m})\end{array}$ & $\begin{array}{c}\text { East } \\
(\mathrm{mm})\end{array}$ & $\begin{array}{c}\text { North } \\
(\mathrm{mm})\end{array}$ \\
\hline $\mathrm{I}$ & 21.903 & 38.444 & 523 & 241 & $\mathbf{4 9 2}$ \\
$\mathrm{J}$ & 21.849 & 38.339 & 6 & 273 & $\mathbf{3 0 7}$ \\
$\mathrm{K}$ & 21.889 & 38.257 & 1050 & 209 & $\mathbf{1 0 1}$ \\
$\mathrm{I} 26$ & 21.919 & 38.392 & 0 & 292 & 466 \\
$\mathrm{I} 8$ & 21.766 & 38.328 & 8 & 507 & $\mathbf{4 3 1}$ \\
$\mathrm{I} 509$ & 21.740 & 38.394 & 509 & 178 & 676 \\
N730 & 21.937 & $\mathbf{3 8 . 3 0 1}$ & 730 & 198 & $\mathbf{1 3 7}$ \\
\hline
\end{tabular}

Source: Briole et al., in preparation, 1997 

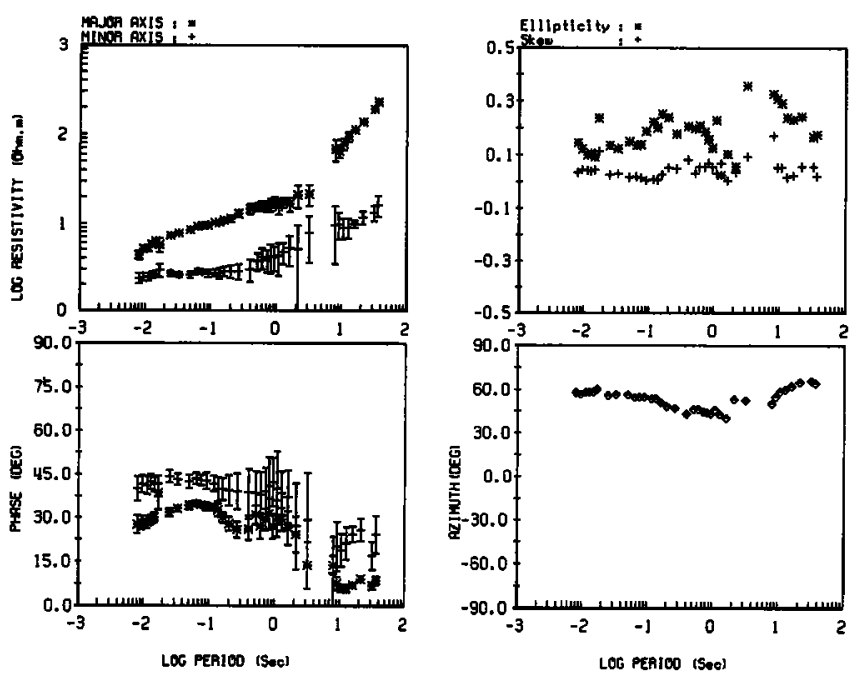

Figure 3. Magnetotelluric results at site 111: (top left) apparent resistivity in the two principal directions versus period. (bottom left) phase versus period. (top right) ellipticity and skew. (bottom right) strike (from north) of the minor axis (maximal conductivity).

the limestone bedrock, associated with a rotation of the principal geoelectric direction, as evidenced by the impedance tensor azimuth. Such a geoelectric structure can be quantitatively interpreted with $1-\mathrm{D}$ tools, to a very fair approximation.

At higher frequencies $(1-10 \mathrm{~Hz})$, one observes a $N 145^{\circ}$ direction of the real induction vector and a $N 55^{\circ} \pm 10^{\circ}$ direction of the maximum electric field, orthogonal at all sites but 222 (Figure 4). Such observations would appear to indicate electric a field propagation in the transverse electric (TE) mode over the relatively conductive part of a laterally inhomogeneous structure with $N 55^{\circ}$ geoelectric strike. The somewhat different behaviour of the electric field at site 222 should probably be attributed to the response of a local, small scale structure. Such properties of the MT field can be observed at periods up to $3 \mathrm{~s}$, which is believed to correspond to the thickness of the delta sediments and the upper, fractured, permeable limestone bedrock.

M'T data alone cannot distinguish a horizontal conductivity anisotropy from near field, lateral inhomogeneities. However, the latter produce a vertical magnetic field, while the former does not. Thus, the significant vertical magnetic field in the bandwidth $0.01-0.3 \mathrm{~s}$ (50\% of the total horizontal field) would indicate either lateral inhomogeneity, or/and dipping anisotropy. The weakly 2-D characteristics of the data also implies that in both cases the geoelectric strike should be the same $\left(N 55^{\circ}\right)$, otherwise significant $3-\mathrm{D}$ effects would have appeared. Assuming that the delta sediments have an approximately horizontal layering, the MT data provide good evidence for the existence of highly conductive, fluid filled macro- and/or micro-structures, either faults or cracks, striking in the $N 55^{\circ}$ direction.

For the upper $1 \mathrm{~km}$ of the sediments, where the deviation from a one-dimensional structure remains small, the quantitative interpretation of the MT data provides longitudinal and transversal conductances (conductivity $x$ depth), which in turn may be considered in terms of longitudinal $\left(N 55^{\circ}\right)$ and transverse $\left(N 145^{\circ}\right)$ porosities by applying Archie's law, under the assumption of saline water fillng the pore spaces. The conductive structure under site 111 leads to a 10-20\% longitudinal and to a 6-10\% transverse porosity. Their difference indicates that under the assumption of a crackinduced anisotropy, the corresponding effective crack volume parallel to $N 55^{\circ}$ is considerably higher than the isotropic pore space. At site 444 , the anisotropy is smaller (6-10\% longitudinal and less than $6 \%$ transverse porosity). At site 222 , the anisotropy is very small and the porosity is 6-8\%. The possibility of higher resistivities with the mixing of fresh water may lead to higher porosity and anisotropy values.

\section{Strain revealed by GPS measurements}

The geodetic studies by Briole et al. (1996; 1997, in preparation) in the Corinth rift have provided precise measurements for 8 geodetic points within $10 \mathrm{~km}$ of the delta, by the comparison of triangulation (1966-1972) with GPS positions (1991-1995) (Table 2 and Figure 4). The estimated uncertainties in the relative displacements are $12 \mathrm{~cm}$. We applied a uniform shift to the original displacements found between the two epochs in order to have point $\mathrm{N} 730$ fixed, in addition to a rotation centered on point $N 730,14.5 \times 10^{-6}$ radians anticlockwise: points $K$ and $J$ then become almost fixed. This procedure introduces no distorsion of the data.

The corrected displacement vectors show a clear opening of this part of the Gulf in the direction NNW-SSW,

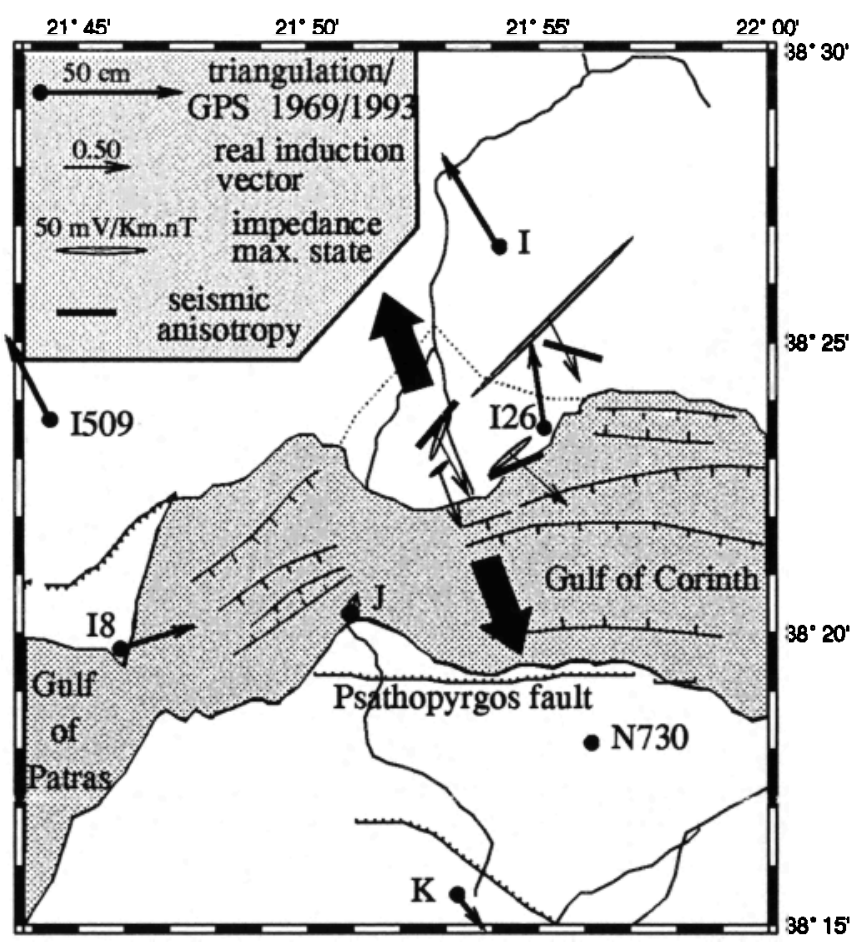

Figure 4. Anisotropy directions and geodetic measurements. Major axis of ellipses give the direction of maximal conductivity. Segments are the fast-S directions. Geodetic displacements are with point N370 fixed). Onshore faults from Armijo et al.(1996). Offshore faults from Papanikolaou et al.(1996). Thick arrows are the local direction of extension deduced from the geodesy. Dotted line is the limit of the delta sediments. All data are consistent with a $N 340^{\circ}$ extension. 
with large displacements of points I $(37 \mathrm{~cm})$, I509 (33 $\mathrm{cm})$, and $126(31 \mathrm{~cm})$ (Figure 4). The relatively inaccurate scaling of the triangulation data of the first epoch introduces an uncertainty in the isotropic component of the strain, but this unknown perturbation has no effect on the deviatoric strain. The latter is of the order of $2 . \times 10^{-6} /$ year (over 24 years), and the maximal extension direction in the vicinity of the delta is $N 340^{\circ} \pm 30^{\circ}$.

\section{Discussion}

All these observations present a very consistent pattern, strongly suggestive of a physical link between them (Figure 4). The electrical and seismic anisotropy is very likely to result from the same anisotropic structure within the soft sediments, which in turn is most probably induced by the reported local strain. We propose that this structure consists of conjugate sets of fractures or faults with steep dip angles, possibly combined with vertical fluid-filled cracks (EDA model), all striking perpendicular to the $N 340^{\circ}$ extension. The porosity estimated above can significantly contribute to the seismic anisotropy under the EDA assumption; however, more refined studies are needed for quantifying the relative importance of the dipping faults and the vertical cracks for generating each of the two measured anisotropies. The cause of this strain and of the related anisotropy is most probably due to the activity of the offshore normal faults recently discovered in the vicinity of the delta (Papanikolaou et al., 1996), and striking $N 60^{\circ}$, as was first suggested by Bouin et al. (1996).

These results provide strong evidence for a significant rotation of the crustal stress direction in the western end of the rift, probably related to the stress perturbation to be expected in the relay zone with the more recently activated Patras gulf to the southwest of the Corinth rift.

From a methodological point of view, we showed that seismic and electrical anisotropy can provide complementary information on the micro- or macro-structure of the shallow crustal rocks. The electrical method seems superior, in several ways, to the seismic one for detecting anisotropy in a horizontally layered media in terms of depth resolution, as shear-wave splitting data usually do not resolve depth, in terms of sensitivity, as electrical anisotropy can be much larger than seismic anisotropy (about 50 times larger in our study), and, finally, in terms of practicality of the measurement, as local earthquakes are rare or nonexistant in many areas. However, these advantages are expected to disappear in more heterogeneous environments, where seismic anisotropy is more robust. Attempts for imaging and monitoring crustal strain with anisotropy studies under the EDA assumption would therefore strongly benefit from the use of both methods in parallel.

Acknowledgments. This study was supported by INSU (France), EC (EPOCH and ENVIRONMENT programs, Seismic risk, contracts \#CT91-0042 and \# EV5V-CT940513, and the PLATON program.

\section{References}

Armijo, R., B. Meyer, G. King, A. Rigo, and D. Papanastassiou, Quaternary evolution of the Corinth rift and its implications for the late Cenozoic evolution of the Aegean, Geophys. J. Int., 126, 11-53, 1996.

Aster, R. C., and P. M. Shearer, Initial shear wave particle motions and stress constraints at the Anza Seismic Network, Geophys. J. Int., 108, 740-748, 1992.

Bouin M.-P., J. Tellez, and P. Bernard, Seismic anisotropy around the Gulf of Corinth, Greece, deduced from threecomponent seismograms of local earthquakes and its relationship with crustal strain, J. Geophys. Res., 101, 5797$5811,1996$.

Booth, D. C., S. Crampin, R. Evans, and G. Roberts, Shear polarizations near the North Anatolian Fault, I, Evidence for anisotropy induced shear wave splitting, Geophys. J. $R$. astr. Soc., 89, 61-73, 1985.

Briole, P., et al., Active deformation of the Gulf of Corinth, Greece: Results from repeated GPS surveys between 1990 and 1996 (abstract), EOS Trans. AGU, 77, 149, 1996.

Crampin, S., Seismic wave propagation through a cracked solid: Polarization as a possible dilatancy diagnostic, Geophys. J. R. astr. Soc. , 53, 467-496, 1978.

Evans, J. R., D. Beamish, S. Crampin, and S. B. Üçer, The Türkish Dilatancy Project (TDP3): multidisciplinary studies of a potential earthquake source region Geophys. J. R. astr. Soc., 91, 265-286, 1987.

Groom, R.W. and R. C. Bailey, Decomposition of the magnetotelluric impedance tensor in the presence of local three-dimensional galvanic distortion, J. Geophys. Res., 94, 1913-1925, 1989.

Papanikolaou, D., G. Chronis, V. Lykousis, D. Sakellariou, and I. Papoulia, Neotectonic structure of the W. Korinthiakos gulf and geodynamical phenomena induced by the Egion earthquake (abstract) Proc. Int. Sci. Symp.: Earthquake, 6.1R, Egio, Aigion, 1996.

Rigo, A., et al., A Microseismic Study in the Western Part of the Gulf of Corinth (Greece): Implications for LargeScale Normal Faulting Mechanisms, Geophys. J. Int, 126, 663-688, 1996.

Tzanis, A., M. Ziazia, D. Kementzetzidou, and K. Makropoulos, A Model of Contemporary Tectonics in SE Thessaly, Greece, as Derived from Magnetotelluric and Seismotectonic Investigations, Proc. XXIV ESC General Assembly, v1, 419-431, 1995.

P. Bernard, P. Briole, and M.-P. Bouin, Institut de Physique du Globe de Paris, 5 Place Jussieu, 75252 Paris, France. (e-mail: bernard@ipgp.jussieu.fr; briole@ipgp.jussieu.fr)

G. Chouliaras, and G. Stavrakakis, National Observatory of Athens, PO Box 20048, 11810 Athens, Greece. (e-mail: g.choul@egelados.gein.noa.gr)

A. Tzanis, and K. Makropoulos, Department of Geophysics and Geothermy, University of Athens, Athens 15784, Greece. (e-mail: g.choul@egelados.gein.noa.gr)

J. Tellez, Departamaneto di Fisica de la Tierra, Universidad Complutense de Madrid, Madrid, 28040, Spain.

(Received April 30, 1997; accepted June 12, 1997.) 